\title{
A Composite Vectors Modulation Strategy for PMSM DTC Systems
}

\author{
Dazhi Wang ${ }^{1}$, Tianqing Yuan ${ }^{1, *} \mathbb{C}$, Xingyu Wang ${ }^{1}$, Xinghua Wang ${ }^{2}$ and Wenhui Li $^{1}$ \\ 1 School of Information Science and Engineering, Northeastern University, Shenyang 110819, China; \\ noblefuture@163.com (D.W.); wangxingyu@stumail.neu.edu.cn (X.W.); wenhuilio@126.com (W.L.) \\ 2 School of Humanities and Law, Northeastern University, Shenyang 110819, China; dm_wxy@126.com \\ * Correspondence: tqyuan@stumail.neu.edu.cn
}

Received: 21 September 2018; Accepted: 10 October 2018; Published: 12 October 2018

\begin{abstract}
The operation performance of permanent magnet synchronous motors (PMSMs) driven by direct torque control (DTC) are affected by torque error compensation and flux error compensation in each control period. The error compensational effects provided by different vectors under different control strategies are analyzed in this paper. The precondition of accurate error compensation is applied to the proposed novel composite vectors modulation strategy (CVM) for a PMSM DTC system. In CVM-DTC, the operating conditions of PMSM are divided into three cases according to the relationships between the errors and the actual error compensations, including steady-state case, dynamic-state case, and transient-state case. In order to establish the novel CVM-DTC strategy smoothly, the effect factors are introduced and used to represent the error compensational effects, which are obtained through the proposed effect factors' controller. The analysis of error compensational effects provided by single active vector and synthetic voltage vector are described in detail while the PMSM is operated in different operation conditions. Finally, the effectiveness of the novel CVM-DTC strategy is verified through the experimental results in a 100-W PMSM drive system.
\end{abstract}

Keywords: permanent magnet synchronous motor (PMSM); direct torque control (DTC); composite vectors modulation (CVM); effect factors

\section{Introduction}

Direct torque control (DTC)-fed permanent magnet synchronous motors (PMSMs) have many merits, including simple construction, high efficiency, and ideal torque control performance. Therefore, PMSM driven by DTC has been applied in electrical drives and industrial applications widely [1-7]. However, because only six active vectors can be applied to compensate torque error and flux error, the PMSM driven by conventional DTC (CDTC) suffers from large torque ripple and flux ripple. Therefore, how to compensate for these errors is the key to improving the operation performance of PMSM. Many researchers have attempted to suppress the ripples through different methods, such as adding the active vector. The added active vector can be obtained through different methods easily, including utilizing a three-level inverter or matrix converter, adopting the duty ratio modulation method, or using decoupled-analysis method on the basis of space vector modulation (SVM) strategy.

Employing more appropriate active vectors during each sampling period, a new DTC strategy based on a three-level voltage-source inverter is proposed for PMSM drive systems [8,9], therefore, the ripples in the PMSM can be reduced effectively. In references [10,11], a PMSM DTC system based on a matrix converter is presented. Based on the redesigned four enhanced switching tables, the ripples of torque and flux in the PMSM can be suppressed effectively. Although more appropriate active vectors can be provided by the three-level inverter or the matrix converter, the cost of the system is inevitably increased. 
As the errors of torque and flux are low in most cases. The errors will be over-compensated if the voltage vector is applied during the whole control period. To solve the above problems, a different duty ratio modulation method is introduced into the PMSM driven by DTC [12-16]. Therefore, torque ripples and flux ripples can be suppressed effectively without degrading the fast dynamic response performance in CDTC. In reference [17], the six basic active vectors provided by a two-level voltage-source inverter are modulated through discrete space vector modulation strategy (DSVM). Therefore, accurate active vectors can be selected from the redesigned switching tables according to torque error and flux error. Although the steady-state performance of the PMSM can be improved by using the DSVM technique, in fact, the errors of torque and flux are compensated by a single active vector with discrete duty ratio modulation.

The currents of stator flux linkage in PMSM are decoupled into $d-q$ axes and controlled independently in field oriented control (FOC), hence satisfactory operating performance can be obtained easily. A novel DTC scheme based on decoupled-analysis strategy is proposed for PMSM, which utilizes a space vector modulation (SVM) strategy [18-25]. With independent control of torque and flux, the amplitude and the phase of the required vector can be accurately obtained through a proportional-integral (PI) regulator or sliding mode observer. Additionally, torque error and flux error can be compensated precisely. On the other hand, the dynamic response of the system will be degraded with the use of a PI regulator or sliding mode observer.

In short, the error compensational effects will affect the performance of the PMSM, therefore, the compensational effects of torque error and flux error in the PMSM driven by different control strategies should be analyzed first. Subsequently, the precondition of accurate error compensation can be obtained. It is worth mentioning that transient-state is the most complicated control process. The high error parameter needs to be compensated fully, and the low error parameter should not be over-compensated, thus, the novel direct torque control method in reference [6] can be used, which considers active angle and impact angle.

In order to obtain the best operation performance of DTC-fed PMSM, a novel composite vectors modulation (CVM) strategy is proposed in this paper. The precondition is adopted in CVM to determine the applied control strategy for the PMSM in different operation conditions, which is ignored in SVM-DTC and CDTC. Experimental results are carried out to validate the effectiveness of the novel CVM-DTC. It is worth mentioning that the steady-state and the dynamic performances of the PMSM which drives by CDTC, DDTC, and SVM-DTC are also discussed in this paper.

The rest of this paper comprises the following sections. The principle of CDTC is described in Section 2. Torque error and flux error compensational effects in the PMSM driven by SVM-DTC are also analyzed in Section 2. The operation conditions dividing criterion for the PMSM and the error compensation effects provided by different vectors are illustrated in Section 3. The accurate error compensation preconditions for the PMSM are also studied in Section 3. The description of the experimental setup and the discussions on the experimental results are described in Section 4. The conclusion is given in Section 5 .

\section{Principle of the Conventional DTC and SVM-DTC}

\subsection{Principle of the Conventional DTC}

Torque error and flux error in the PMSM can be compensated through eight voltage vectors, which are provided by a two-level voltage source inverter, containing six active vectors $V_{n}(n=1,2,3,4$, $5,6)$ and two null vectors $\left(V_{0}\right.$ and $\left.V_{7}\right)$. The spatial placements of the six active vectors in $\alpha \beta$-reference frames are shown in Figure 1. The section boundary lines $l_{i}(i=1,2,3,4,5,6)$ are used to divide the rotation space of stator flux linkage $F_{s}$, as shown in Figure 1 . Number " $N$ " is used to represent the divided six sectors, and the active vector in which the stator flux linkage $F_{s}$ is located is represents by the sector vector $V_{s}$. 


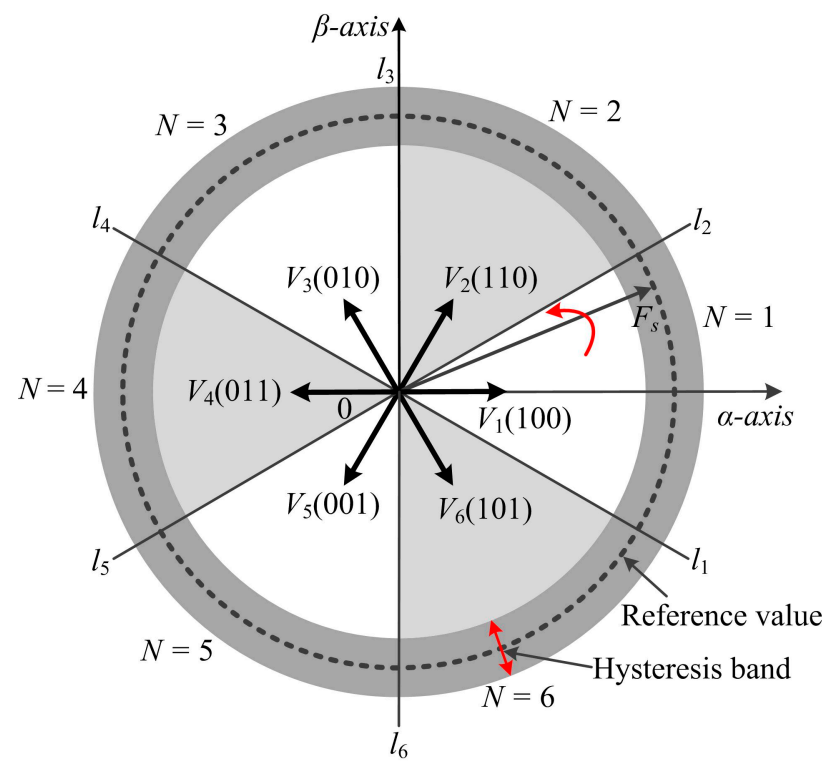

Figure 1. Active vectors in direct torque control (DTC) system.

The reference value $T_{\text {ref }}$ and the real-time value $T$ are used to obtain torque error $e_{T}$, and the property $\varepsilon_{T}$ value of torque error $e_{T}$ will be determined through the hysteresis comparator.

The property value of $\varepsilon_{T}$ is 1 or -1 , which indicates that torque $T$ needs to be increased if the $\varepsilon_{T}$ is 1 , while torque $T$ needs to be decreased if $\varepsilon_{T}$ is -1 . The determination process of another parameter flux $F$ is done in the same way. The selection rules for the active vectors in CDTC are shown in Table 1.

Table 1. Conventional switching table.

\begin{tabular}{cccc}
\hline \multirow{2}{*}{ Sector Number $N$} & & \multicolumn{2}{c}{ Torque $\left(\varepsilon_{T}\right)$} \\
\cline { 3 - 4 } & & $\mathbf{1}$ & $\mathbf{1}$ \\
\hline \multirow{2}{*}{ Stator flux linkage $\left(\varepsilon_{F}\right)$} & 1 & $V_{N+1}$ & $V_{N-1}$ \\
& -1 & $V_{N+2}$ & $V_{N-2}$ \\
\hline
\end{tabular}

\subsection{Compensations of Torque Error and Flux Error in a SVM-DTC System}

In CDTC, the active vectors have fixed amount and direction, hence the torque error and the flux error are difficult to reduce accurately, leading to unsatisfactory steady-state performance. To reduce the large ripples in DTC-fed PMSM, the decoupled control method is adopted, which is used in FOC-fed PMSM. The PI controllers are adopted to gain the torque vector and the flux vector based on torque error and flux error. Finally, the accurate vector can be determined through space vector modulation (SVM).

Figure 2 shows the errors of torque and flux in SVM-DTC system. The stator flux linkage changes from $F_{s 1}$ to $F_{s 2}$ during one control period. And the variation of the stator flux linkage is $\Delta F_{s}$, which can be decoupled into $\Delta F_{s d}$ and $\Delta F_{s q}$ in the $d$ - $q$ axis. The wanted voltage vectors $u_{q s}$ and $u_{d s}$ are obtained through the PI controllers based on torque error $\Delta T$ and flux error $\Delta F$.

From the above analysis, it can be found that the PI controllers are used in SVM-DTC to determine the accurate vectors, instead of the use of switching table in CDTC. Additionally, it is not necessary to compensate torque error and flux error through the vectors selected from the six basic active vectors. Therefore, the operation performance of the PMSM can be improved effectively. Although the precise of the accurate synthetic vector can be obtained through the SVM strategy in the PMSM driven by SVM-DTC, the dynamic response of the system will be affected inevitably. 


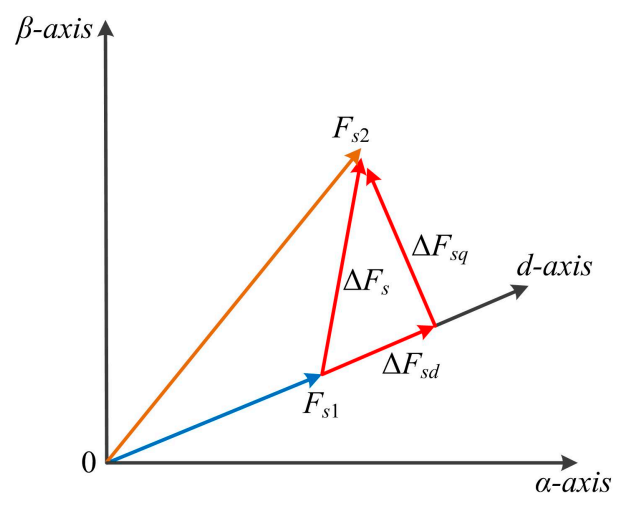

Figure 2. Errors of torque and flux in the $d-q$ reference frame.

\section{Analysis of Error Compensation}

Torque error and flux error are relatively minor in the SVM-DTC-fed PMSM system, while the PMSM is operated in a steady-state condition. However, the dynamic response will be affected by complex calculations of synthesis voltage vector or over-modulation process while the PMSM is operated in the condition of dynamic-state. This is the main reason why the dynamic response of SVM-DTC-fed PMSM is weaker than that of CDTC.

In order to obtain the best steady-state performance and dynamic response of the PMSM, the control strategy should be adjusted on the basis of the operation conditions of the PMSM. Therefore, the differences of the error compensations supplied by the synthesis voltage vector in SVM-DTC and the single active vector in CDTC under different operation conditions are analyzed in this section.

\subsection{Operation Conditions}

In one control period, the torque error and the flux error are $\Delta T$ and $\Delta F$, respectively. In this case, the torque parameter variation is $\Delta F_{s q}$, and the amplitude parameter variation is $\Delta F_{s d}$, as shown in Figure 3.

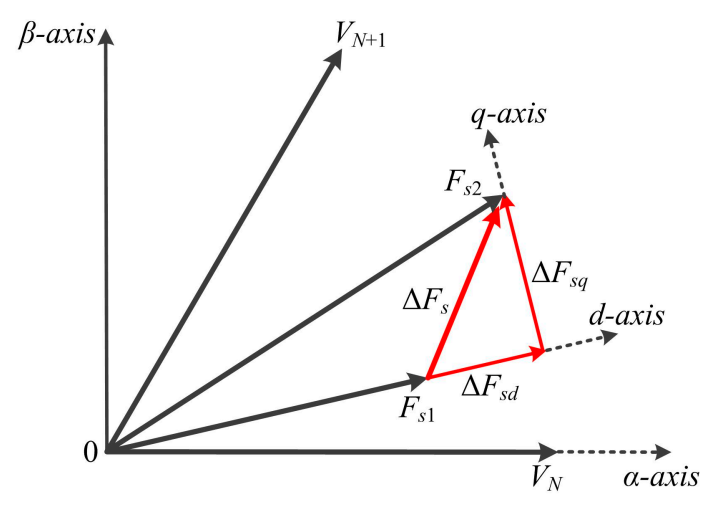

Figure 3. Analysis of error compensational effects.

The torque and amplitude component variations of the stator flux linkage can be expressed as

$$
\begin{gathered}
\Delta F_{s q}=\frac{2 L_{s}}{3 p} \cdot \frac{1}{F_{f}} \cdot \Delta T \\
\Delta F_{s d}=\Delta F
\end{gathered}
$$

where $L_{s}$ is the stator inductance, $p$ is the number of pole pairs, and $F_{f}$ is the permanent magnet flux linkage. 
During the entire sampling period, the torque parameter compensation supplied by the applied vector is $\Delta F_{s q}^{\prime}$, and the amplitude parameter compensation is $\Delta F_{s d}^{\prime}$, as shown in Figure 4.

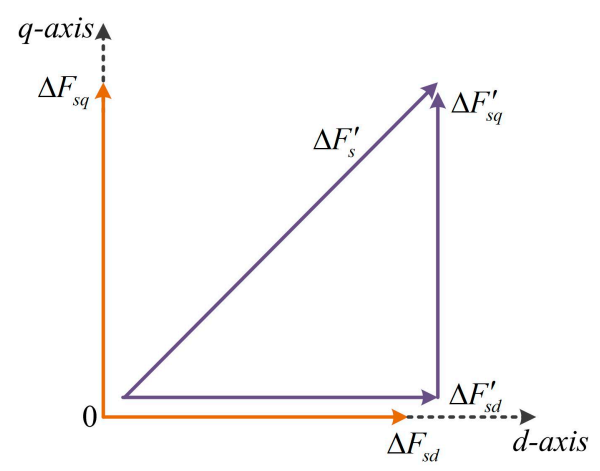

Figure 4. Analysis of error compensational effects.

It is obvious that the values of $\Delta F_{s q}^{\prime}$ and $\Delta F_{s d}^{\prime}$ are fixed in each control period. While torque error $\Delta T$ and flux error $\Delta F$ are different with the varying of the stator flux linkage's $F_{s}$ location in different sampling period. Hence, the actual errors values of $\Delta F_{s q}$ and $\Delta F_{s d}$ are different in different control period.

The relationship between the actual error compensations and the errors are described in the following way.

First item, the errors are lower than the actual compensations:

$$
\left(\begin{array}{c}
\Delta F_{s d}<\Delta F_{s d}^{\prime} \\
\Delta F_{s q}<\Delta F_{s q}^{\prime}
\end{array}\right.
$$

Second item, the errors are greater than the actual compensations:

$$
\left(\begin{array}{rl}
\Delta F_{s d} & >\Delta F_{s d}^{\prime} \\
\Delta F_{s q} & >\Delta F_{s q}^{\prime}
\end{array}\right.
$$

Third item, the flux error is greater than the actual compensation while the torque error is less than the actual compensation:

$$
\left(\begin{array}{c}
\Delta F_{s d}>\Delta F_{s d}^{\prime} \\
\Delta F_{s q}<\Delta F_{s q}^{\prime}
\end{array}\right.
$$

Fourth item, the flux error is lower than the actual compensation while the torque error is greater than the actual compensation:

$$
\left(\begin{array}{l}
\Delta F_{s d}<\Delta F_{s d}^{\prime} \\
\Delta F_{s q}>\Delta F_{s q}^{\prime}
\end{array}\right.
$$

The operating conditions of the PMSM can be divided into three items on the basis of the errors and the actual compensations, as shown in Table 2.

Table 2. Operation conditions.

\begin{tabular}{cc}
\hline Operation Conditions & Reference Equation \\
\hline Steady-state & $(3)$ \\
Transient-state & $(5)$ and (6) \\
Dynamic-state & $(4)$ \\
\hline
\end{tabular}




\subsection{Error Compensation Analysis in Steady-State Case}

The torque error $\Delta T$ and the flux error $\Delta F$ are relatively low in the steady-state [6]. It should be noted that the compensations of the stator flux linkage supplied by the single active vector $V_{N}$ or the synthesis voltage vector are $\Delta F_{s 1}^{\prime}$ and $\Delta F_{s}^{\prime}$, respectively, as shown in Figure 5 . The angle between the stator flux linkage error $\Delta F_{S}$ and the active vector $V_{N}$ is $\theta_{1}$. It is obvious that both torque error and flux error compensations are higher than the errors. Therefore, the errors will be over-compensated if the active vector or the synthesized voltage vector is applied over the whole control period.

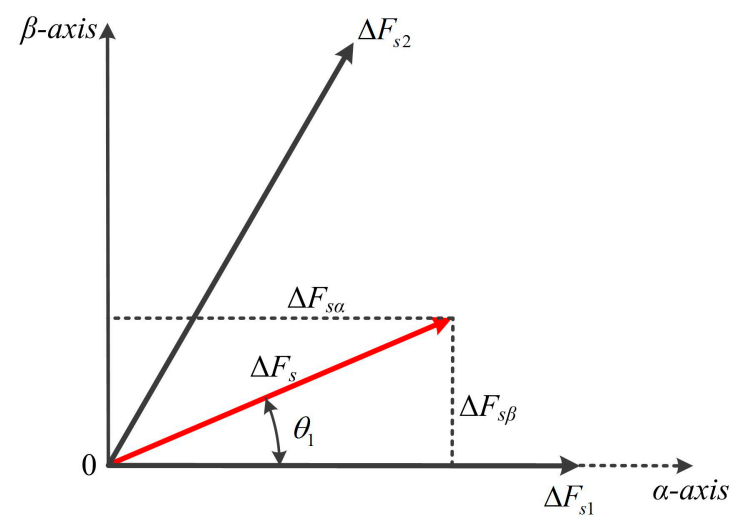

Figure 5. Analysis of error compensational effects in steady-state.

In the PMSM driven by duty ratio direct torque control (DDTC), the applied time of the active vector is modulated through a duty ratio modulation strategy. Although the over-compensation of the errors can be avoided in DDTC-fed PMSM, the fixed active vectors limit the compensational effects.

In the SVM-DTC-fed PMSM, the adjacent active vectors $V_{N}$ and $V_{N+1}$ can be selected as the benchmark vectors. Furthermore, an accurate synthesized voltage vector can be obtained. $T_{1}$ and $T_{2}$ are used to represent the applied time of $V_{N}$ and $V_{N+1}$, respectively. Therefore, the error compensations can be calculated as:

$$
\begin{gathered}
\Delta F_{s 1}^{\prime}=V_{N} \cdot T_{1} \\
\Delta F_{s 2}^{\prime}=V_{N+1} \cdot T_{2}
\end{gathered}
$$

The active vectors modulation process can be given by:

$$
\begin{gathered}
\Delta F_{s 1}^{\prime}+\Delta F_{s 2}^{\prime} \cdot \cos \frac{\pi}{3}=\Delta F_{s \alpha}=\Delta F_{s} \cdot \cos \theta_{1} \\
\Delta F_{s 2}^{\prime} \cdot \sin \frac{\pi}{3}=\Delta F_{s \beta}=\Delta F_{s} \cdot \sin \theta_{1} \\
T_{1}+T_{2}+T_{0}=T_{s}
\end{gathered}
$$

where $T_{0}$ is the applied time of zero voltage vector.

From above analysis, it can be observed that torque error and flux error can be compensated effectively through SVM while the PMSM is operated in the steady-state.

\subsection{Error Compensation Analysis in Dynamic-State Case}

The torque error $\Delta T$ or the flux error $\Delta F$ of the PMSM will become greater in dynamic-state while the speed or the torque varies. As shown in Figure 6, the stator flux linkage error is $\Delta F_{s}$, and the angle between the active vector $V_{N}$ and the stator flux linkage error $\Delta F_{S}$ is $\theta_{2}$. It is obvious that the error compensations are lower than the torque error and the flux error.

It can be observed that single active vector $V_{n}$ or the synthesized voltage vector cannot supply the full compensations to torque error $\Delta T$ and flux error $\Delta F$ in next control period. 
The differences of error compensational effect provided by synthesized voltage vector or single active vector are described in this section.

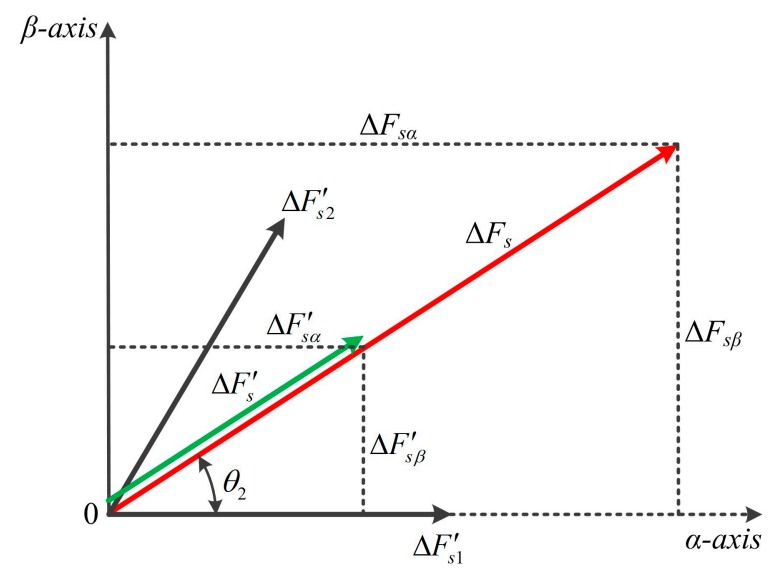

Figure 6. Analysis of error compensational effects in dynamic-state.

\subsubsection{Synthetic Voltage Vector}

The benchmark vectors are composed of the adjacent active vectors $V_{N}$ and $V_{N+1}$, and $T_{1}$ and $T_{2}$ are the applied time of $V_{N}$ and $V_{N+1}$, respectively. Consequently, the error compensations can be given by:

$$
\begin{gathered}
\Delta F_{s 1}^{\prime}=V_{N} \cdot T_{1} \\
\Delta F_{s 2}^{\prime}=V_{N+1} \cdot T_{2} \\
\Delta F_{s 1}^{\prime}+\Delta F_{s 2}^{\prime} \cdot \cos \frac{\pi}{3}=\Delta F_{s \alpha}=\Delta F_{s} \cdot \cos \theta_{2} \\
\Delta F_{s 2}^{\prime} \cdot \sin \frac{\pi}{3}=\Delta F_{s \beta}=\Delta F_{s} \cdot \sin \theta_{2}
\end{gathered}
$$

Since the errors are greater than the actual compensations,

$$
T_{1}+T_{2}>T_{S}
$$

The applied time of the applied active vectors can be over-modulated as:

$$
\begin{aligned}
& T_{1}^{\prime}=\frac{T_{1}}{T_{1}+T_{2}} \cdot T_{S} \\
& T_{2}^{\prime}=\frac{T_{2}}{T_{1}+T_{2}} \cdot T_{S}
\end{aligned}
$$

The applied time of the applied active vectors can be simplified as:

$$
\begin{aligned}
& T_{1}=k_{1} \cdot T_{S} \\
& T_{2}=k_{2} \cdot T_{S}
\end{aligned}
$$

Furthermore, the actual compensation of the stator flux linkage can be described as:

$$
\begin{gathered}
\Delta F_{s \alpha}^{\prime}=V_{N} \cdot \frac{k_{1}}{k_{1}+k_{2}} \cdot T_{s}+V_{N+1} \cdot \cos \frac{\pi}{3} \cdot \frac{k_{2}}{k_{1}+k_{2}} \cdot T_{s} \\
\Delta F_{s \beta}^{\prime}=V_{N+1} \cdot \sin \frac{\pi}{3} \cdot \frac{k_{2}}{k_{1}+k_{2}} \cdot T_{s}
\end{gathered}
$$


which can be rewritten as:

$$
\left(\begin{array}{l}
\Delta F_{s \alpha}^{\prime}=V_{N} \cdot T_{s} \cdot\left(\frac{k_{1}}{k_{1}+k_{2}}+\frac{1}{2} \cdot \frac{k_{2}}{k_{1}+k_{2}}\right) \\
\Delta F_{s \beta}^{\prime}=V_{N} \cdot T_{s} \cdot \frac{\sqrt{3}}{2} \cdot \frac{k_{2}}{k_{1}+k_{2}}
\end{array}\right.
$$

Consequently, the compensation of the stator flux linkage supplied by the synthesized voltage vector can be evaluated by:

$$
\left|\Delta F_{s}^{\prime}\right|=\sqrt{\left(\Delta F_{s \alpha}^{\prime}\right)^{2}+\left(\Delta F_{s \beta}^{\prime}\right)^{2}}=V_{N} \cdot T_{s} \cdot \sqrt{\frac{k_{1}^{2}+k_{1} k_{2}+k_{2}^{2}}{\left(k_{1}+k_{2}\right)^{2}}}<V_{N} \cdot T_{S}
$$

\subsubsection{Single Active Vector $V_{n}$}

The compensations of the stator flux linkage provided by the adjacent vectors $V_{N}$ and $V_{N+1}$ over the entire control period are:

$$
\begin{gathered}
\Delta F_{s 1}^{\prime \prime}=V_{N} \cdot T_{s} \\
\Delta F_{s 2}^{\prime \prime}=V_{N+1} \cdot T_{S}
\end{gathered}
$$

The compensations of the stator flux linkage supplied by the single active vector can be defined as:

$$
\Delta F_{s}^{\prime \prime}=\Delta F_{s 1}^{\prime \prime}=\Delta F_{s 2}^{\prime \prime}=V_{N} \cdot T_{s}
$$

The comparison result of the stator flux linkage compensations provided by different vectors can be written as:

$$
\Delta F_{s}^{\prime}<\Delta F_{s}^{\prime \prime}
$$

From above analysis, it can be found that the compensational effects of the stator flux linkage provided by a single active vector is greater than synthesized voltage vector. Therefore, the SVM strategy is not necessary to compensate these errors while the PMSM is operated in the dynamic state. In order to simplify the complicated calculations in the system, the appropriate active vector $V_{n}$ can be selected from the switching table and be applied in the control system during the whole control period.

In conclusion, torque error and flux error can be compensated through the CDTC strategy while the PMSM is operated in the dynamic state. Thus, the delayed dynamic response can be eliminated which is caused by the introduced PI controller, and the ripples' depressing effects of the PMSM driven by CDTC are the same as that driven by SVM-DTC.

\subsection{Error Compensation Analysis in Transient-State Case}

External disturbance will cause the operating condition of the PMSM to deviate from the steady-state. Therefore, the operation condition may turn into transient-state if one component of torque error or flux error is large while another component is relatively low.

The torque error $\Delta T$ is high and the flux error $\Delta F$ is relatively low as shown in Figure 7. The variation of the stator flux linkage is $\Delta F_{s}$.

The differences of the error compensation effect supplied by single active vector $V_{n}$ or synthesized voltage vector $u_{s}$ are described in the following section. 


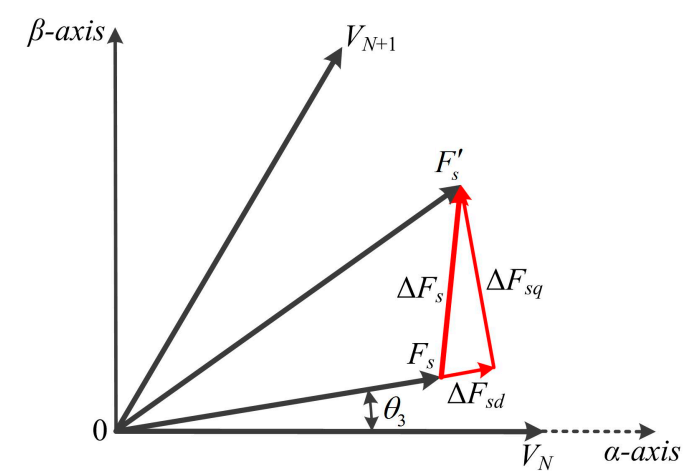

Figure 7. Analysis of error compensational effects in transient-state.

\subsubsection{Synthetic Voltage Vector}

Figure 8 shows the error compensations supplied by different active vectors.

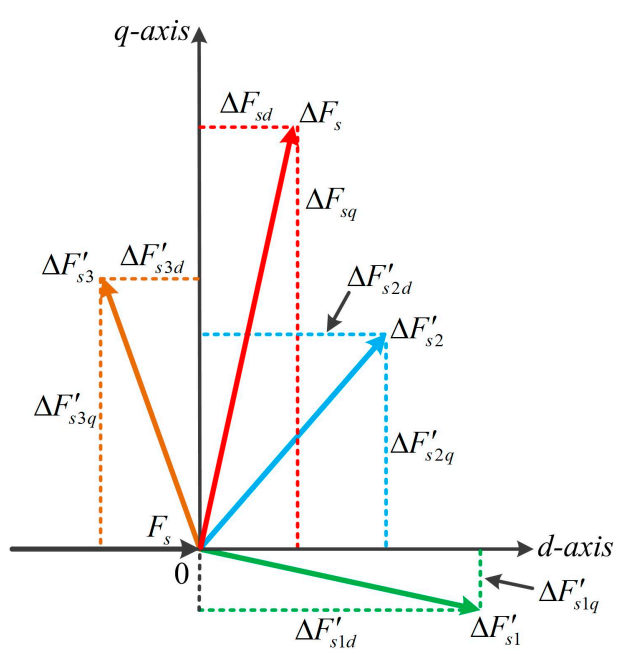

Figure 8. Analysis of error compensational effects provided by different active vectors.

As shown in Figure 8, the benchmark vectors are composed of the adjacent active vectors $V_{N+1}$ and $V_{N+2}$. And $T_{1}$ and $T_{2}$ are the applied time of $V_{N+1}$ and $V_{N+2}$, respectively. The error compensations are calculated as

$$
\begin{gathered}
\Delta F_{s 2 q}^{\prime} \cdot T_{1}+\Delta F_{s 3 q}^{\prime} \cdot T_{2}=\Delta F_{s q} \cdot T_{s} \\
\Delta F_{s 2 d}^{\prime} \cdot T_{1}-\Delta F_{s 3 d}^{\prime} \cdot T_{2}=\Delta F_{s q} \cdot T_{s} \approx 0
\end{gathered}
$$

\subsubsection{Single Active Vector $V_{n}$}

As shown in Figure 8, the stator flux linkage error $\Delta F_{s}$ is located in the middle of compensations $\Delta \varphi_{s 2}^{\prime}$ and $\Delta \varphi_{s 3}^{\prime}$. In order to compensate the torque error component $\Delta F_{s q}$ effectively and avoid the over-compensation of the flux error component $\Delta F_{s d}$ at the same time, the adjacent vectors $V_{N+1}$ and $V_{N+2}$ should be chosen and half of the sampling period applied.

From the aforementioned analyses, it can be observed that the torque error can be compensated fully supplied by the single active vector $V_{n}$ while the PMSM is operated in the condition of transient-state, nevertheless, the flux error cannot be compensated effectively. Although the errors of torque and flux can be compensated effectively by the synthetic voltage vector $u_{s}$, the calculations of the system are inevitably increased. It is worth mentioning that the problem that one parameter is large and another parameter is relatively low can be solved through the novel DDTC strategy in reference [1], which considered the active angel. Consequently, the novel DDTC strategy can be 
applied to compensate the errors in the control system while the PMSM is operated in the condition of transient-state.

\subsection{Novel Composite Active Vectors Modulation Strategy}

In order to improve both the steady-state performance and dynamic response of the PMSM, a novel composite vector modulation DTC (CVM-DTC) strategy is proposed for the control system, which considers the differences of the error compensations in different operation conditions. The schematic diagram of the CVM-DTC system is shown in Figure 9.

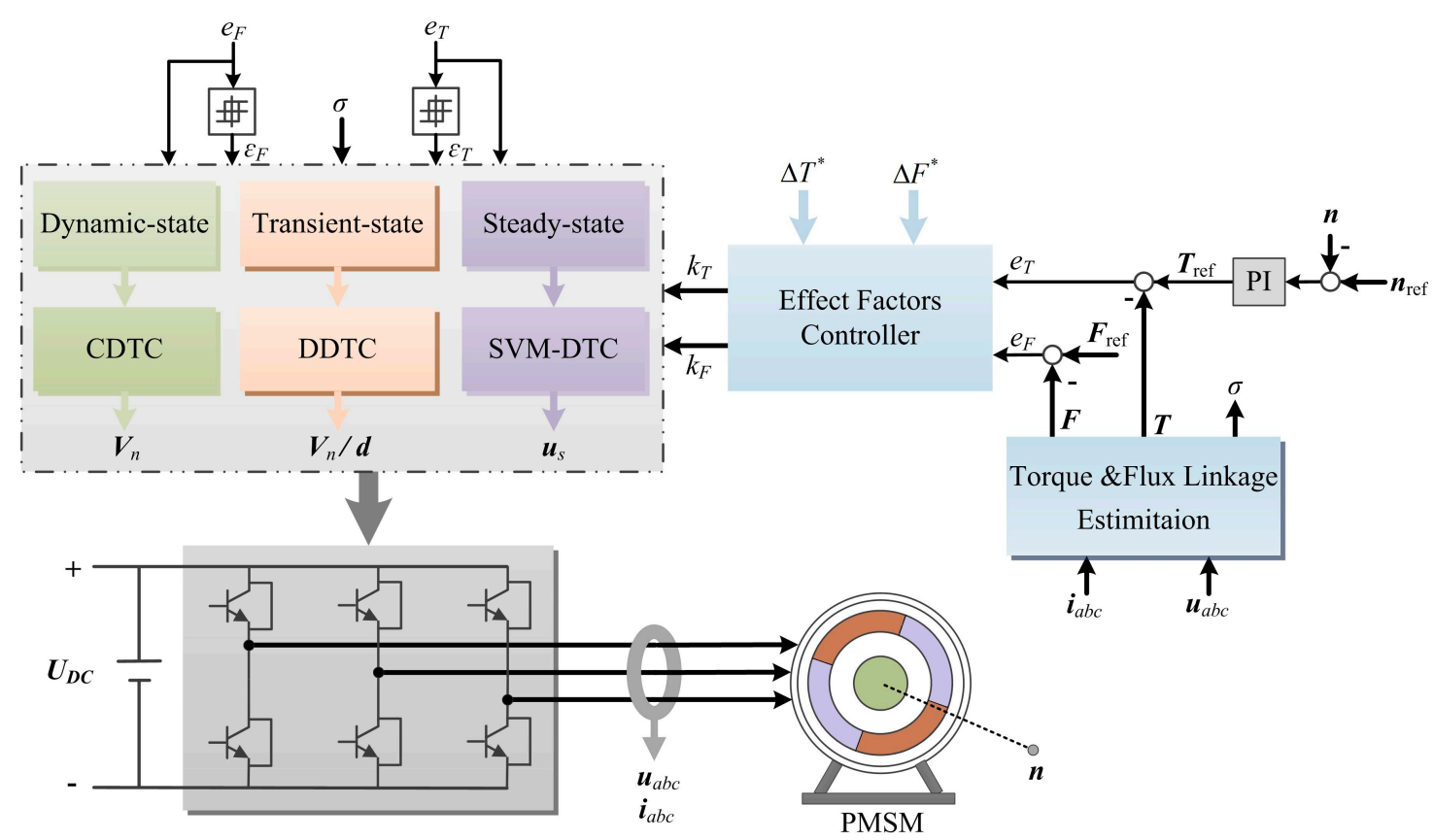

Figure 9. Schematic diagram of the composite vector modulation DTC (CVM-DTC) for a permanent magnet synchronous motor (PMSM).

In order to reduce the ripples of torque and flux linkage in the system effectively and maintain fast dynamic response performance, an appropriate control strategy should be selected from the three control strategies on the basis of the operating conditions of the PMSM and applied to the control system.

The precondition of the accurate error compensation is: the errors of torque and flux can be compensated fully provided by the applied active vector during the entire control period. On the other hand, this precondition is not considered in SVM-DTC. Additionally, the errors of torque and flux are analyzed through decoupled calculations by PI controllers. The compensations of the stator flux linkage in SVM-DTC systems and CDTC systems while the PMSM is operated in the condition of non-steady-state are nearly the same. In conclusion, the compensational effects for torque error and flux error are not satisfied without considering the operation conditions of the PMSM, and the dynamic response will also be affected.

\subsection{Determining of the Operation Condition through FLC}

It is worth mentioning that the accurate calculation of effect factors is the key to determining the operation condition of the PMSM, therefore, a feedback linearization control (FLC) strategy is adopted to eliminate the influences on the accurate effect factors calculations caused by external disturbance in the system. 
$\Delta T^{*}$ and $\Delta F^{*}$ are the reference values of torque variation and flux variation, respectively, which can be given by

$$
\begin{gathered}
\Delta T^{*}=\Delta T_{\max }=\frac{3 p}{2 L_{s}} \cdot F_{f} \cdot V_{n} \cdot T_{s} \\
\Delta F^{*}=\Delta F_{d \max }=V_{n} \cdot T_{s}
\end{gathered}
$$

Define the compensation rates of torque and flux are $E_{T}$ and $E_{F}$, respectively. The effect factors controller will adjust the effect factors $k_{T}$ and $k_{F}$ based on the input of $e_{T}$ and $e_{F}$ through the proposed effect factors controller as shown in Figure 10, which can be expressed as:

$$
\left[\begin{array}{l}
k_{F} \\
k_{T}
\end{array}\right]=\left[\begin{array}{ll}
l_{F} & \\
& l_{T}
\end{array}\right] E
$$

where

$$
E=\left[\begin{array}{c}
E_{F} \\
E_{T}
\end{array}\right]=\left[\begin{array}{ll}
f_{F} & \\
& f_{T}
\end{array}\right]\left[\begin{array}{l}
e_{F} \\
e_{T}
\end{array}\right]-\left[\begin{array}{ll}
g_{F} & \\
& g_{T}
\end{array}\right]\left[\begin{array}{c}
k_{T} \\
k_{F}
\end{array}\right]+\left[\begin{array}{c}
\Delta F^{*} \\
\Delta T^{*}
\end{array}\right]
$$

and $l_{F}, l_{T}, f_{F}, f_{T}, g_{F}$, and $g_{T}$ are the constant gains that are settled on the basis of the parameters in the PMSM.

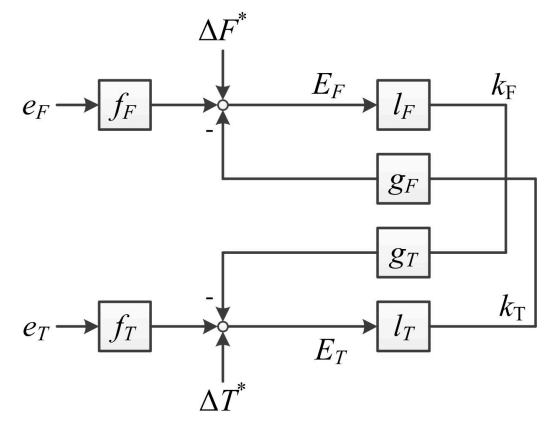

Figure 10. Structure of the proposed effect factors controller.

The relationships between the effect factors and the operation conditions of the PMSM are described in Table 3.

Table 3. Effect factors for different operation conditions.

\begin{tabular}{ccc}
\hline \multicolumn{2}{c}{ Effect Factors } & Operation Conditions \\
\cline { 1 - 2 }$k_{T}$ & $k_{\boldsymbol{F}}$ & \\
\hline \multirow{3}{*}{$(-\infty,-1)$} & $(-\infty,-1)$ & Dynamic-state \\
& $(1,+\infty)$ & Transient-state \\
& $(-\infty,-1)$ & Dynamic-state \\
\hline & $(-1,1)$ & Transient-state \\
& $(1,+\infty)$ & Steady-state \\
& $(-\infty,-1)$ & Transient-state \\
\hline & $(-1,1)$ & Dynamic-state \\
& $(1,+\infty)$ & Transient-state \\
& & Dynamic-state \\
\hline
\end{tabular}

\section{Experimental Analysis}

\subsection{Experimental System Setup}

Experimental studies are carried out on a 100-W PMSM drive system to validate the feasibility and effectiveness of the novel CVM-DTC. The experimental hardware setup is illustrated in Figure 11. 
The parameters of the PMSM are given as follows: $R_{S}=0.76 \Omega ; L_{S}=0.00182 \mathrm{H}$; the number of pole pairs $p=4$. The DC voltage is $36 \mathrm{~V}$. A 1024-pulse incremental encoder is installed to obtain the rotor mechanical speed and position. The load is applied using a magnetic powder brake. This section compares the steady-state performance and the dynamic response of the PMSM driven by CDTC, SV-DDTC, SVM-DTC, or CVM-DTC. The experiments are implemented in a TMS320F28335 DSP (Digital Signal Processing) control system (Texas Instruments, Dallas, America) with a sampling period of $100 \mu \mathrm{s}$.

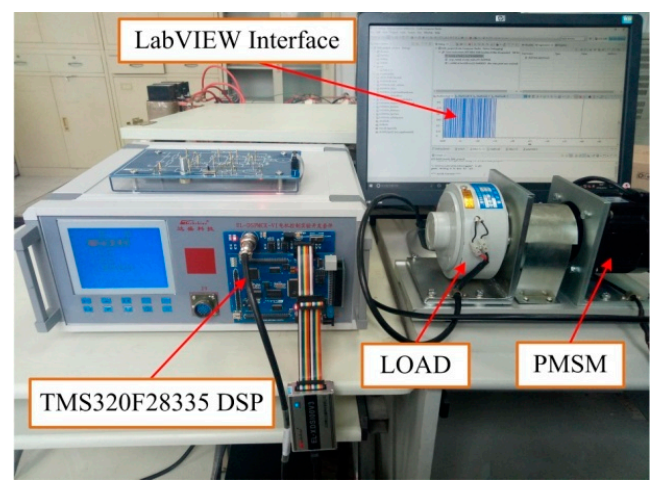

Figure 11. Experimental setup of the control system.

\subsection{Dynamic Performance}

In order to validate the fast dynamic response of the novel CVM-DTC, the speed responses of the PMSM driven by the four different control strategies are studied while the torque is set as $0.5 \mathrm{~N} \cdot \mathrm{m}$. In these tests, a step change from 200 to $400 \mathrm{rpm}$ is applied on the speed reference. The experimental results are shown in Figure 12.

It can be found that the rotor speed ripple is $35 \mathrm{rpm}$ with the using of CDTC, while the rotor speed ripples are 30, 25, and $24 \mathrm{rpm}$ when using DDTC, SVM-DTC, and CVM-DTC, respectively. Additionally, the rotor speed settling time with the four control strategies are $0.013,0.012,0.019$, and $0.012 s$, respectively.

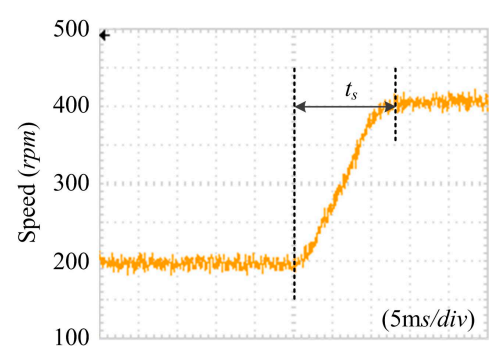

(a)

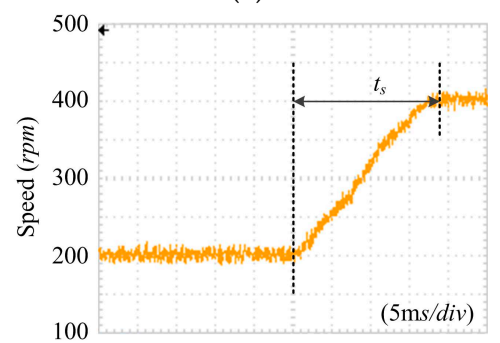

(c)

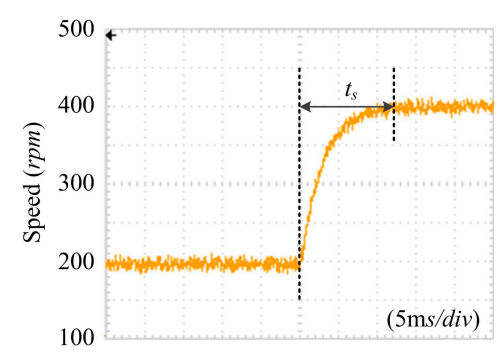

(b)

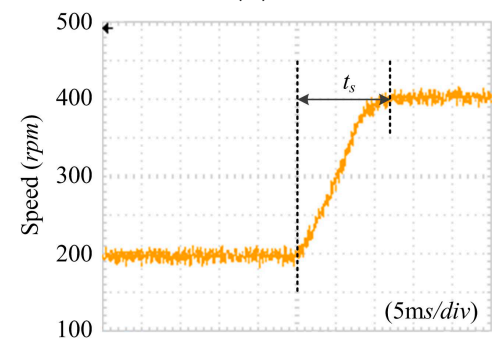

(d)

Figure 12. The speed trajectory from $200 \mathrm{rpm}$ to $400 \mathrm{rpm}$ when using: (a) conventional DTC (CDTC); (b) duty ratio direct torque control (DDTC); (c) space vector modulation DTC (SVM-DTC); (d) CVM-DTC. 
In conclusion, the main advantage in CDTC, i.e., the fast dynamic response, can be maintained in novel CVM-DTC. Experimental results show that dynamic response has higher priority than ripples in the condition of dynamic-state, thus DDTC or SVM-DTC should be abandoned. In this case, the applied control strategy in CVM-DTC in dynamic-state condition is appropriate.

\subsection{Steady-State Performance}

The steady-state performances of CDTC, DDTC, SVM-DTC, and CVM-DTC are compared under the same operating conditions. The PMSM is operated at $300 \mathrm{rpm}$ and the reference values of torque and flux are $1 \mathrm{~N} \cdot \mathrm{m}$ and $0.3 \mathrm{~Wb}$, respectively. The torque and flux waveforms of the PMSM driven by different control strategies are shown in Figure 13.
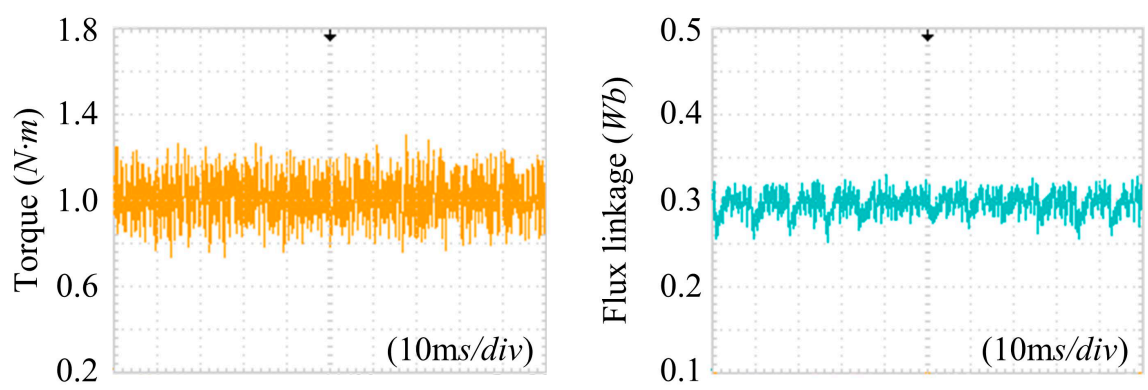

(a)
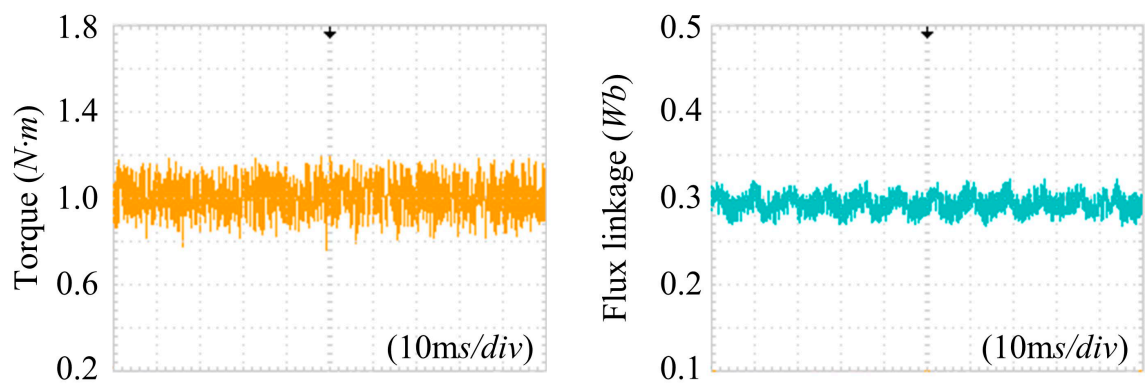

(b)
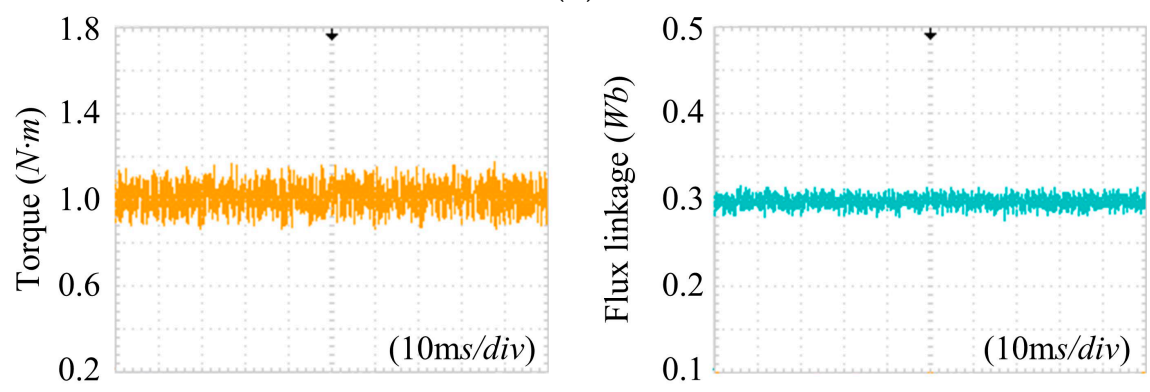

(c)
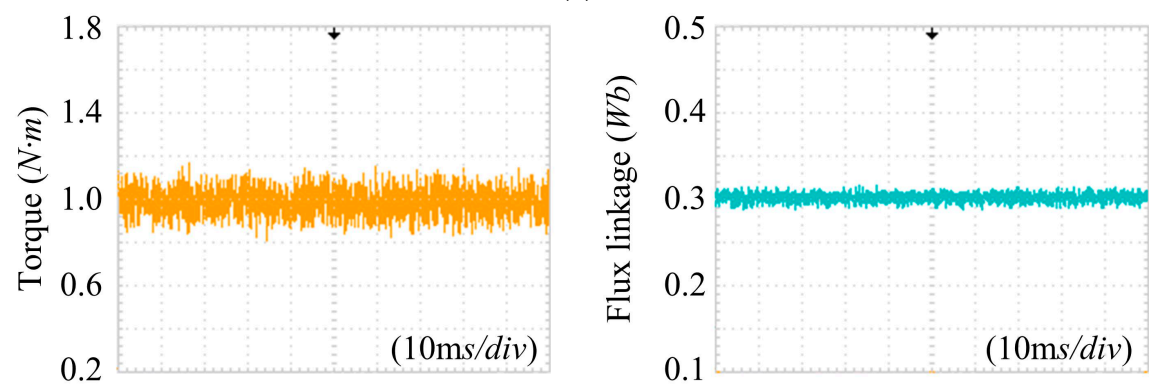

(d)

Figure 13. Experimental torque and flux of the PMSM when using: (a) CDTC; (b) DDTC; (c) SVM-DTC; (d) CVM-DTC. 
Experimental results show that the torque ripples of the PMSM driven by CDTC, DDTC, SVM-DTC, and CVM-DTC are 0.6, 0.44, 0.32, and $0.34 \mathrm{~N} \cdot \mathrm{m}$, respectively, and the flux ripples of the PMSM are $0.08,0.055,0.035$, and $0.032 \mathrm{~Wb}$, respectively. Consequently, compared with CDTC, DDTC and SVM-DTC can suppress torque ripple by at least $27 \%$ and $46 \%$, respectively, and suppress flux ripple at least $25 \%$ and $50 \%$, respectively. The steady-state performances of the PMSM driven by CVM-DTC in the same setting operation condition are nearly the same as SVM-DTC. The experimental results show that torque error and flux error can be compensated through SVM-DTC, which indicates that the selected control strategy for the CVM-DTC system in the condition of steady-state is appropriate.

\section{Conclusions}

The precondition of accurate error compensation is studied in this paper. We found that the errors of torque and flux can be compensated fully, provided by the applied active vector during the entire control period. It is obvious that this precondition will affect the operation performance of the PMSM directly, therefore, this precondition is adopted in the proposed CVM-DTC scheme.

Consequently, the error compensational effects supplied by different vectors are analyzed while the PMSM is operated in different operation conditions. Then, the effect factor is introduced to represent the obtained error compensation effects. Furthermore, effect factors are used to divide the operation conditions of the PMSM. It should be noted that dynamic response has higher priority than ripples in the condition of dynamic-state, thus, DDTC or SVM-DTC should be abandoned. In this case, applying CVM-DTC in the dynamic-state condition is appropriate. Furthermore, the steady-state performances of the PMSM driven by CVM-DTC in the same setting operation condition are nearly the same as with SVM-DTC. Hence, torque error and flux error can be compensated through SVM-DTC, which indicates that the selected control strategy for the CVM-DTC system in the steady-state is appropriate. To obtain the best operation performance, the most appropriate control strategy is determined on the basis of effect factors and is applied to compensate the errors in PMSM.

Experimental results indicate that the proposed CVM-DTC exhibits satisfactory steady-state performance with lower ripples of torque and flux when compared to CDTC and DDTC, and faster dynamic response when compared to SVM-DTC.

Author Contributions: This paper was a collaborative effort between the authors. T.Y., D.W., X.W. (Xingyu Wang), X.W. (Xinghua Wang), and W.L. proposed the original idea; T.Y. wrote the full manuscript and carried out the experiments.

Funding: This research received no external funding.

Acknowledgments: This work was supported in part by National Natural Science Foundation of China under Grant 61433004 and 51467017, and in part by National Key Research and Development Program of China under Grant 2017YFB1300900.

Conflicts of Interest: The authors declare no conflict of interest.

\section{References}

1. Cheema, M.A.M.; Fletcher, J.E.; Xiao, D.; Rahman, M.F. A direct thrust control scheme for linear permanent magnet synchronous motor based on online duty ratio control. IEEE Trans. Power Electron. 2016, 31, 4416-4428. [CrossRef]

2. Abosh, A.; Zhu, Z.Q.; Ren, Y. Reduction of torque and flux ripples in space vector modulation-based direct torque control of asymmetric permanent magnet synchronous machine. IEEE Trans. Power Electron. 2017, 32, 2976-2986. [CrossRef]

3. Zhou, Y.Z.; Chen, G.T. Predictive DTC strategy with fault-tolerant function for six-phase and three-phase PMSM series-connected drive system. IEEE Trans. Ind. Electron. 2018, 65, 9101-9112. [CrossRef]

4. Shinohara, A.; Inoue, Y.; Morimoto, S.; Sanada, M. Direct calculation method of reference flux linkage for maximum torque per ampere control in DTC-based IPMSM drives. IEEE Trans. Power Electron. 2016, 32, 2114-2122. [CrossRef] 
5. Alsofyani, I.M.; Idris, N.R.N.; Lee, K.B. Dynamic hysteresis torque band for improving the performance of lookup-table-based DTC of induction machines. IEEE Trans. Power Electron. 2018, 33, 7959-7970. [CrossRef]

6. Yuan, T.Q.; Wang, D.Z.; Li, Y.L. Duty ratio modulation strategy to minimize torque and flux linkage ripples in IPMSM DTC system. IEEE Access 2017, 5, 14323-14332. [CrossRef]

7. Putri, A.K.; Rick, S.; Franck, D.; Hameyer, K. Application of sinusoidal field pole in a permanent-magnet synchronous machine to improve the NVH behavior considering the MTPA and MTPV operation area. IEEE Trans. Ind. Appl. 2016, 52, 2280-2288. [CrossRef]

8. Tatte, Y.N.; Aware, M.V.; Pandit, J.K.; Nemade, R. Performance improvement of three-level five-phase inverter-fed DTC-controlled five-phase induction motor during low-speed operation. IEEE Trans. Ind. Appl. 2018, 54, 2349-2357. [CrossRef]

9. Payami, S.; Behera, R.K.; Iqbal, A. DTC of three-level NPC inverter fed five-phase induction motor drive with novel neutral point voltage balancing scheme. IEEE Trans. Power Electron. 2018, 33, 1487-1500. [CrossRef]

10. Xia, C.; Zhao, J.; Yan, Y.; Shi, T. A novel direct torque and flux control method of matrix converter-fed PMSM drives. IEEE Trans. Power Electron. 2014, 29, 5417-5430. [CrossRef]

11. Yan, Y.; Zhao, J.; Xia, C.; Shi, T. Direct torque control of matrix converter-fed permanent magnet synchronous motor drives based on master and slave vectors. IET Power Electron. 2015, 8, 288-296. [CrossRef]

12. Mohan, D.; Zhang, X.; Foo, G.H.B. A simple duty cycle control strategy to reduce torque ripples and improve low-speed performance of a three-level inverter fed DTC IPMSM drive. IEEE Trans. Ind. Electron. 2017, 64, 2709-2721. [CrossRef]

13. Niu, F.; Wang, B.; Babel, A.S.; Li, K.; Strangas, E.G. Comparative evaluation of direct torque control strategies for permanent magnet synchronous machines. IEEE Trans. Power Electron. 2016, 31, 1408-1424. [CrossRef]

14. Zhang, Y.; Zhu, J.; Xu, W.; Guo, Y. A simple method to reduce torque ripple in direct torque-controlled permanent-magnet synchronous motor by using vectors with variable amplitude and angle. IEEE Trans. Ind. Electron. 2011, 58, 2848-2859. [CrossRef]

15. Ren, Y.; Zhu, Z.Q.; Liu, J. Direct torque control of permanent-magnet synchronous machine drives with a simple duty ratio regulator. IEEE Trans. Ind. Electron. 2014, 61, 5249-5258. [CrossRef]

16. Niu, F.; Li, K.; Wang, Y. Direct torque control for permanent magnet synchronous machines based on duty ratio modulation. IEEE Trans. Ind. Electron. 2015, 62, 6160-6170. [CrossRef]

17. Xu, A.; Zhao, X.; He, K.; Cao, Y. Torque-ripple reduction of SRM using optimized voltage vector in DTC. IET Electr. Syst. Transp. 2018, 8, 35-43.

18. Mohan, D.; Zhang, X.; Foo, G. Generalized DTC strategy for multilevel inverter fed IPMSMs with constant inverter switching frequency and reduced torque ripples. IEEE Trans. Energy Convers. 2017, 32, 1031-1041. [CrossRef]

19. Zhang, Z.; Zhao, Y.; Qiao, W.; Qu, L. A space-vector-modulated sensorless direct-torque control for direct-drive PMSG wind turbines. IEEE Trans. Ind. Appl. 2014, 50, 2331-2341. [CrossRef]

20. Zhang, X.; Foo, G.H. Over-modulation of constant switching frequency based DTC for reluctance synchronous motors incorporating field-weakening operation. IEEE Trans. Ind. Electron. 2019, 66, 37-47. [CrossRef]

21. Berzoy, A.; Rengifo, J.; Mohammed, O. Fuzzy predictive DTC of induction machines with reduced torque ripple and high performance operation. IEEE Trans. Power Electron. 2018, 33, 2580-2587. [CrossRef]

22. Do, T.D.; Choi, H.H.; Jung, J.W. Nonlinear Optimal DTC Design and Stability Analysis for Interior Permanent Magnet Synchronous Motor Drives. IEEE/ASME Trans. Mechatron. 2015, 20, 2716-2725. [CrossRef]

23. Choi, Y.-S.; Choi, H.H.; Jung, J.W. Feedback linearization direct torque control with reduced torque and flux ripples for IPMSM drives. IEEE Trans. Power Electron. 2016, 31, 3728-3737. [CrossRef]

24. Zhang, Z.; Wei, C.; Qiao, W.; Qu, L. Adaptive saturation controller-based direct torque control for permanent-magnet synchronous machines. IEEE Trans. Power Electron. 2016, 31, 7112-7122. [CrossRef]

25. Liang, D.L.; Li, J.; Qu, R.H.; Kong, W.B. Adaptive second-order sliding-mode observer for PMSM sensorless control considering VSI nonlinearity. IEEE Trans. Power Electron. 2018, 33, 8994-9004. [CrossRef]

(C) 2018 by the authors. Licensee MDPI, Basel, Switzerland. This article is an open access article distributed under the terms and conditions of the Creative Commons Attribution (CC BY) license (http:/ / creativecommons.org/licenses/by/4.0/). 